\title{
Pulmonary hypertension in idiopathic pulmonary fibrosis: epidemiology, diagnosis and therapeutic implications
} \author{
Steven D. Nathan \\ Published online: 11 September 2012 \\ (C) Springer Science+Business Media, LLC 2012
}

John Sherner • Jacob Collen • Christopher S. King •

\begin{abstract}
A significant proportion of patients with idiopathic pulmonary fibrosis have concurrent pulmonary hypertension. In most, elevations in pulmonary pressures are modest, but approximately $10 \%$ have disproportionately elevated pulmonary pressures. Pulmonary hypertension is associated with decreased functional status and increased mortality. The etiology remains incompletely understood, but likely involves a complex interplay of abnormal angiogenesis, vascular ablation, remodeling, and vasoconstriction. Transthoracic echocardiogram, six-minute walk testing, pulmonary function testing and biomarkers may suggest pulmonary hypertension, but none are sensitive or specific enough to rule in or exclude the diagnosis. Right heart catheterization remains the diagnostic gold standard. Supplemental oxygen should be provided if required and sleep-disordered breathing should be addressed. Small trials suggest that vasodilator therapy may improve exercise tolerance, but no mortality benefit has been demonstrated. Patients with disproportionate pulmonary hypertension
\end{abstract}

\author{
J. Sherner $\cdot$ C. S. King \\ Ft. Belvoir Community Hospital, Pulmonary/Critical Care \\ Medicine, \\ Fairfax County, VA, USA \\ J. Sherner \\ e-mail: John.sherner@us.army.mil \\ C. S. King \\ e-mail: Csking123@hotmail.com \\ J. Collen \\ Walter Reed National Military Medical Center, Pulmonary/Critical \\ Care Medicine, \\ Bethesda, MD, USA \\ e-mail: jcollen2002@gmail.com

\section{S. D. Nathan $(\square)$} \\ Department of Medicine, Inova Fairfax Hospital, Advanced Lung \\ Disease and Lung Transplant Program, \\ Falls Church, VA, USA \\ e-mail: steven.nathan@inova.org
}

should be encouraged to enroll in clinical trials of vasodilator therapy so that the role of these agents can be better defined. Ultimately, genetic profiling technology may serve to individualize therapy in such patients.

Keywords Idiopathic pulmonary fibrosis · Pulmonary hypertension $\cdot$ Interstitial lung disease $\cdot$ Chronic lung disease

\section{Introduction}

The Idiopathic Pulmonary Fibrosis Clinical Research Network recently published the results of the PANTHER-IPF trial, a study designed to assess the efficacy of the combination of prednisone, azathioprine, and $\mathrm{N}$-acetylcysteine in patients with idiopathic pulmonary fibrosis (IPF). The trial was halted early due to an increased rate of death in the treatment group [1]. This study represents the most recent disappointment in the search for a medical therapy for IPF, a progressive fibrotic disorder of the lungs of unknown cause, with no universally recognized effective medical therapy. IPF affects between 14 and 43 per 100,000 persons in the United States and has a dismal prognosis, with an estimated median survival of 2.5 to 5 years from the time of diagnosis [2].

While effective medical therapies for IPF remain elusive, significant progress has been made in the understanding of the various phenotypic presentations of the disease and the underlying pathophysiology of each. One key phenotype that holds potential for possible therapeutic inroads is that of IPF with associated pulmonary hypertension ( $\mathrm{PH})$. Aside from the possibility of the development of novel therapies for this specific IPF phenotype, recognition of PH in IPF is essential, as associated $\mathrm{PH}$ negatively affects functional status and outcomes [3]. In this article, we will review the medical literature on the epidemiology, pathophysiology, and optimal diagnostic and therapeutic approach to PH in IPF. 


\section{Definition}

The most recent clinical consensus guidelines on $\mathrm{PH}$ were derived during the World Symposium on Pulmonary Hypertension held in Dana Point, CA, USA in 2008. These guidelines define $\mathrm{PH}$ as a resting mean pulmonary artery pressure (mPAP) $\geq 25 \mathrm{mmHg}$, assessed by right heart catheterization (RHC) [4]. PH associated with IPF is categorized as group 3: "Pulmonary hypertension due to lung diseases and/or hypoxia." Of note, the diagnosis of $\mathrm{PH}$ based on an $\mathrm{mPAP} \geq 30 \mathrm{mmHg}$ during exercise is not supported by the current guidelines, which cite a lack of published data to support this definition. Patients with $\mathrm{mPAP} \geq 40 \mathrm{mmHg}$ are characterized as "out-of-proportion" $\mathrm{PH}$, and likely represent a distinct phenotype from patients with more modest elevations in mPAP [4].

While the guidelines help to standardize definitions for the purpose of research, these definitions may fail to capture all clinically important effects of pulmonary hemodynamics in IPF. For instance, a lower mPAP than required for a diagnosis of PH may be clinically significant. Hamada and colleagues prospectively followed a group of $61 \mathrm{IPF}$ patients with RHC data from the time of diagnosis up to a maximum of 14 years. They found that a mPAP threshold of $>17 \mathrm{mmHg}$ was associated with significantly worsened 5 year survival ( $62.2 \%$ vs. $16.7 \%, p<0.001)$ [5]. Additionally, although data on pulmonary artery pressures (PAP) during exercise are somewhat limited, exercise-induced changes in PAP in IPF appear to have significant implications $[6,7]$. Weitzenblum et al. assessed hemodynamics and arterial blood gas readings in 31 patients with IPF. They found an increase in mPAP from $21.7 \pm 7.8 \mathrm{mmHg}$ to $45.3 \pm 16.2 \mathrm{mmHg}$ and a drop in partial pressure of arterial oxygen $\left(\mathrm{PaO}_{2}\right)$ from $69.6 \pm$ $11.6 \mathrm{mmHg}$ to $56.0 \pm 9.4 \mathrm{mmHg}$ with exercise [8]. While the guidelines fail to recognize exercise-induced $\mathrm{PH}$ as a distinct pathological phenomenon, further research is required to determine the clinical significance of this entity.

\section{Prevalence}

The prevalence of PH in IPF is poorly defined, with reports in the literature ranging from as low as $8.1 \%$ to as high as $86.4 \%$ [5, 9-23]. Table 1 summarizes the available studies and their characteristics. There are numerous reasons for the significant disparities between studies. One reason is the methodology used to determine PH. Transthoracic echo (TTE) appears to be unreliable for the diagnosis of PH in IPF, so prevalence data obtained with TTE may be inaccurate $[17,24]$. Another issue is the nature of the study populations. The bulk of the data obtained via RHC has been performed in patients referred for evaluation for lung transplantation. Patients within these cohorts are likely younger, have fewer comorbidities, and may have more severe respiratory disease than patients not referred for transplant evaluation. Finally, significant variability in pulmonary pressures may exist depending on the timing of assessment in the disease process. This was demonstrated in a cohort of 44 patients with serial measurements of PAP by Nathan et al. Only $38.6 \%$ of these patients had PH at baseline assessment, but $86.4 \%$ had PH by the time of transplant [18]. The prevalence of disproportionate $\mathrm{PH}$ is even less well defined, with reports ranging from $9.0 \%$ to $31.0 \%[16,23,25]$. Further study is required to determine the prevalence and predictors of disproportionate $\mathrm{PH}$.

\section{Impact of PH in IPF}

\section{Exercise capacity}

A lower six-minute-walk distance (6MWD) has been associated with decreased survival in IPF [12]. Numerous studies have demonstrated an association between $\mathrm{PH}$ and decreased 6MWD [13, 16, 22, 23]. Lettieri et al. compared patients with and without $\mathrm{PH}$ as assessed by RHC and found a statistically significant decrease in both 6MWD (143.5 \pm $65.5 \mathrm{~m}$ vs. $365.9 \pm 81.8 \mathrm{~m}, p<0.001)$ and mean pulse oximetric saturation nadir during six-minute-walk test (6MWT) $(80.1 \pm 3.7 \%$ vs. $88.0 \pm 3.5 \%, p<0.001)$ [13]. Boutou and colleagues performed cardiopulmonary exercise testing on 81 patients with IPF. They found that a systolic pulmonary artery pressure (PASP) $>35 \mathrm{mmHg}$ on TTE was associated with a decreased maximum work rate achieved and peak oxygen consumption $\left(\mathrm{VO} 2_{\max }\right)$ in comparison to patients without PH [21]. Based on these studies, it appears that PH significantly impacts exercise tolerance in a negative fashion.

\section{Effect of transplantation outcomes}

The effect of secondary PH in IPF patients on transplantation outcomes is an area of debate due to heterogeneity in study outcomes and the limitations of available studies. Although some studies have found no impact of $\mathrm{PH}$ on outcomes [26-28], there is evidence that preoperative $\mathrm{PH}$ may increase the risk of death following single lung transplantation in IPF [29]. Additionally, other studies have demonstrated an increased risk for primary graft dysfunction in the context of pre-existing PH $[30,31]$.

\section{Mortality}

PH has consistently been demonstrated to adversely affect survival in IPF $[9,13]$. Nadrous et al. demonstrated a negative correlation between survival and PASP on TTE with median survival rates of $4.8,4.1$, and 0.7 years for patients with 
Table 1 Studies reporting prevalence data on pulmonary hypertension in IPF

\begin{tabular}{|c|c|c|c|c|c|c|}
\hline Study & $\begin{array}{l}\text { Patient } \\
\text { Number }\end{array}$ & Patient Population & PH Definition & \% with $\mathrm{PH}$ & $\begin{array}{l}\% \text { with } \\
\text { severe PH }\end{array}$ & Comments \\
\hline King et al. 2001 [9] & 238 & $\begin{array}{l}\text { Enrolled in prospective } \\
\text { study at referral center }\end{array}$ & $\begin{array}{l}\text { Radiographic evidence } \\
\text { of } \mathrm{PH} \text { on } \mathrm{CXR}\end{array}$ & $20.0 \%$ & Not reported & $\begin{array}{l}\text { Presence of } \mathrm{PH} \text { on } \mathrm{CXR} \\
\text { associated with increased } \\
\text { mortality }\end{array}$ \\
\hline Agarwal et al. 2005 [10] & 25 & Referral center & $\mathrm{sPAP}>40 \mathrm{mmHg}$ by TTE & $36.0 \%$ & Not reported & $\begin{array}{l}\text { Symptomatic patients } \\
\text { excluded }\end{array}$ \\
\hline Nadrous et al. 2005 [11] & 88 & $\begin{array}{l}\text { Initial evaluation at } \\
\text { referral center }\end{array}$ & $\begin{array}{l}\text { sPAP }>35 \mathrm{mmHg} \text { by } \\
\text { TTE; Severe PH }=\text { sPAP } \\
>50 \mathrm{mmHg} \text { by TTE }\end{array}$ & $84.0 \%$ & $31.0 \%$ & $\begin{array}{l}\text { Worsened survival when } \\
\text { SPAP }>50 \mathrm{mmHg}\end{array}$ \\
\hline Lederer et al. 2006 [12] & 376 & $\begin{array}{l}\text { Review of patients listed } \\
\text { for transplant on UNOS }\end{array}$ & $\mathrm{mPAP}>25 \mathrm{mmHg}$ & $36.0 \%$ & Not reported & \\
\hline Lettieri et al. 2006 [13] & 79 & $\begin{array}{l}\text { Lung transplant and IPF } \\
\text { referral center; } \\
\text { Retrospective }\end{array}$ & $\mathrm{mPAP}>25 \mathrm{mmHg}$ & $31.6 \%$ & Not reported & $\begin{array}{l}\text { Linear correlation between } \\
\text { mPAP and mortality }\end{array}$ \\
\hline Hamada et al. 2007 [5] & 70 & $\begin{array}{l}\text { University Hospital; } \\
\text { Initial evaluation }\end{array}$ & $\mathrm{mPAP}>25 \mathrm{mmHg}$ & $8.1 \%$ & Not reported & $\begin{array}{l}\text { Worsened outcomes with } \\
\mathrm{mPAP}>17 \mathrm{mmHg}\end{array}$ \\
\hline Nathan et al. 2007 [14] & 118 & $\begin{array}{l}\text { Retrospective review at } \\
\text { referral center }\end{array}$ & $\mathrm{mPAP}>25 \mathrm{mmHg}$ & $40.7 \%$ & Not reported & \\
\hline Shorr et al. 2007 [16] & 2,525 & Lung transplant registry & $\begin{array}{l}\mathrm{mPAP}>25 \mathrm{mmHg} \\
\text { Severe } \mathrm{PH}=\mathrm{mPAP} \\
>40 \mathrm{mmHg}\end{array}$ & $46.1 \%$ & $9.0 \%$ & $\begin{array}{l}\text { Need for } \mathrm{O}_{2} \text {, age, ethnicity, } \\
\text { FEV1, } \mathrm{PCO}_{2}, \mathrm{PCWP} \\
\text { associated with severe } \mathrm{PH}\end{array}$ \\
\hline Daniels et al. 2008 [15] & 42 & Autopsy data & Autopsy evidence of PH & $45.0 \%$ & Not reported & \\
\hline Nathan et al. 2008 [17] & 110 & $\begin{array}{l}\text { Retrospective review at } \\
\text { two referral centers }\end{array}$ & $\mathrm{mPAP}>25 \mathrm{mmHg}$ & $34.5 \%$ & Not reported & $\begin{array}{l}\text { Study designed to assess } \\
\text { TTE vs RHC for PH } \\
\text { determination }\end{array}$ \\
\hline Nathan et al. 2008 [18] & 44 & $\begin{array}{l}\text { Comparison of RHC data } \\
\text { from time of transplant } \\
\text { to initial evaluation }\end{array}$ & $\mathrm{mPAP}>25 \mathrm{mmHg}$ & $86.4 \%$ & Not reported & $\begin{array}{l}38.6 \% \text { at initial evaluation; } \\
\text { Increased to } 86.4 \% \text { by } \\
\text { time of transplant }\end{array}$ \\
\hline Todd et al. 2010 [19] & 41 & $\begin{array}{l}\text { Retrospective review at } \\
\text { referral center of ILD } \\
\text { patients; IPF data } \\
\text { extracted }\end{array}$ & $\mathrm{mPAP}>25 \mathrm{mmHg}$ & $29.3 \%$ & Not reported & \\
\hline $\begin{array}{l}\text { Modrykamien } \\
\text { et al. } 2010 \text { [20] }\end{array}$ & 58 & $\begin{array}{l}\text { Retrospective review of } \\
\text { transplanted patients at } \\
\text { referral center }\end{array}$ & $\begin{array}{l}\mathrm{mPAP}>25 \mathrm{mmHg} \text { and } \\
\mathrm{PCWP}<15 \mathrm{mmHg}\end{array}$ & $43.0 \%$ & Not reported & \\
\hline Boutou et al. 2011 [21] & 81 & $\begin{array}{l}\text { Retrospective analysis of } \\
\text { referral center data }\end{array}$ & $\mathrm{sPAP}>35 \mathrm{mmHg}$ by TTE & $57.0 \%$ & Not reported & $\begin{array}{l}\text { Resting sPAP correlated } \\
\text { with impaired exercise } \\
\text { capacity }\end{array}$ \\
\hline $\begin{array}{l}\text { Papakosta, et al. } \\
2011 \text { [22] }\end{array}$ & 139 & $\begin{array}{l}\text { Prospective analysis at } \\
\text { eight referral centers }\end{array}$ & $\mathrm{sPAP}>36 \mathrm{mmHg}$ by TTE & $55.0 \%$ & Not reported & \\
\hline Anderson et al. 2012 [23] & 49 & $\begin{array}{l}\text { Prospective analysis of } \\
\text { ILD patients; IPF data } \\
\text { extracted }\end{array}$ & $\begin{array}{l}\text { TTE screen; RHC if TTE } \\
\text { suggestive; mPAP }>25 \\
\text { mmHg; severe } \\
\mathrm{PH}=\mathrm{mPAP}>35 \mathrm{mmHg}\end{array}$ & $24.5 \%$ & $14.2 \%$ & $\begin{array}{l}\text { May underestimate } \\
\text { prevalence as only } \\
\text { TTE + referred for RHC }\end{array}$ \\
\hline
\end{tabular}

Not all studies designed specifically to assess $\mathrm{PH}$ prevalence

$C X R$ Chest radiography; ILD Interstitial lung disease; IPF Idiopathic pulmonary fibrosis; $m P A P$ mean pulmonary artery pressure; $P C W P$ Pulmonary capillary wedge pressure; $P H$ pulmonary hypertension; $s P A P$ systolic pulmonary artery pressure; $R H C$ right heart catheterization; TTE Transthoracic echo; UNOS United Network for Organ Sharing

PASP of $<35 \mathrm{mmHg}, 36-50 \mathrm{mmHg}$, and $>50 \mathrm{mmHg}$, respectively [11]. A similar study by Song and colleagues found one year mortality rates of $61.2 \%$ for patients with PASP $>40$ $\mathrm{mmHg}$ vs. $19.9 \%$ in those with $\mathrm{PASP}<40 \mathrm{mmHg}$ [32].

Another IPF phenotype is combined IPF/emphysema. It is controversial as to whether these patients have worse or better outcomes than IPF patients without emphysema; however, what is well established is that this particular phenotype does have a greater propensity for $\mathrm{PH}$. This makes sense from the standpoint that both pathologically distinct processes have the destruction of the pulmonary vasculature in common [33]. The importance of acute exacerbations of IPF (AE-IPF) on mortality has been recognized in recent years. A report by Judge et al. found PH to be a 
significant risk factor for AE-IPF $(\mathrm{HR}=2.217, p=0.041)$ [34]. This association is possibly partially responsible for the adverse outcomes seen with IPF-associated PH.

\section{Pathophysiology of pulmonary hypertension in IPF}

PH in IPF was long thought to be due to the effects of hypoxic vasoconstriction and pulmonary capillary loss due to progressive fibrosis [35]. Hypoxic vasoconstriction leads to changes in vessel walls, including medial and intimal hypertrophy [36]. While hypoxic vasoconstriction almost certainly plays a role in PH in IPF, it cannot be the sole mechanism, as PH may develop in patients without hypoxemia [37]. Progressive destruction of the pulmonary vascular bed likely also contributes to the development of PH. Fibrosis in IPF is a heterogeneous process. In fibrotic areas, thickening of arterial and venous walls and severe luminal narrowing occurs, leading to increased pulmonary vascular resistance [38]. If progressive fibrosis were the primary mechanism leading to the development of PH in IPF, one would expect a correlation between the degree of restriction on pulmonary function testing and the development of PH. This relationship has not borne out, implying that other mechanisms contribute to pulmonary vascular disease in IPF [3].

If these two mechanisms alone fail to explain the pathogenesis of PH in IPF, then what mechanisms are responsible? Although incompletely understood, a complex interplay of multiple factors appears to be at work. A disruption in the balance of angiogenesis occurs, due to decreases in angiogenic factors such as vascular endothelial growth factor (VEGF) and an elevation of angiostatic factors including pigment-endothelium derived factor (PEDF). This may lead to decreased vascularity in fibrotic areas and hypervascularity in adjacent nonfibrotic areas. This leads to a net decrease in overall vessel density in the IPF lung [3]. Fibrotic regions may have both apoptotic and proliferating endothelial cells, resulting in anastomoses between alveolar capillaries and pulmonary veins [35]. Additionally, vessels in fibrotic regions may lack an elastin layer, reducing their capacitance and further contributing to $\mathrm{PH}$ [39].

A number of mediators responsible for the pathogenesis of fibrosis in IPF have been implicated in the development of PH as well. Profibrogenic leukotrienes, increased production of tumor necrosis factor $\alpha$ (TNF- $\alpha$ ), platelet-derived growth factor (PDGF) and fibroblast growth factor, may all be involved in the development of both pulmonary vascular remodeling and fibrogenesis [40]. Endothelin-1 (ET-1) is both a potent vasoconstrictor and stimulator of smooth muscle cell proliferation [3]. These factors offer the potential for a therapeutic target that modifies both the fibrogenic and pulmonary vascular disease aspects of IPF. Unfortunately, the antifibrotic effects of endothelin antagonists have not been borne out in two recent large, prospective studies [41, 42].
Diagnosis

The diagnosis of pulmonary hypertension in the setting of IPF can be difficult. However, there is a growing interest in the evaluation for PH in IPF patients, given the important prognostic information imparted and the opportunity to rule out other contributory and modifiable factors, such as diastolic dysfunction. Additionally, there is ongoing interest in the diagnosis of "out of proportion PH," since this might be the specific sub-phenotype most amenable to trials of vasoactive therapies.

Signs and symptoms of PH in IPF patients are nonspecific and may be subtle, since the PH is often mild. Physical exam findings such as a tricuspid regurgitant murmur, a loud pulmonary component of the second heart sound, or a RV heave, are unusual and therefore are not sufficiently sensitive to diagnose PH. Likewise, EKG may show signs of right heart strain, but this finding also lacks sensitivity and specificity for predicting $\mathrm{PH}$.

RHC with direct measurement of pressures has been the gold standard for the diagnosis. However the invasive nature of this procedure is not ideal for routine assessment and serial follow-up to assess therapeutic response. Thus, there has been great interest in the development of a noninvasive measure to diagnose pulmonary hypertension. Past efforts focused on the use of spirometry, the single breath diffusing capacity for carbon monoxide $\left(\mathrm{DL}_{\mathrm{CO}}\right)$ and 6MWT, to predict the presence of $\mathrm{PH}$. Multiple investigators have demonstrated that spirometric values do not distinguish which IPF patients have $\mathrm{PH}$ [14]. However, the $\mathrm{DL}_{\mathrm{CO}}$ may have some value in this regard, especially once it decreases to $<40 \%$ of predicted. The use of noninvasive indicators in parallel can improve the performance characteristics and accuracy for predicting $\mathrm{PH}$. For example, the combination of $\mathrm{DL}_{\mathrm{CO}}<40 \%$ predicted and resting room air saturation $<88 \%$ has been shown to be predictive of $\mathrm{PH}$, with positive and negative predictive value of $87 \%$ and $82 \%$, respectively [13].

Given the failure of spirometry and limitations of the $\mathrm{DL}_{\mathrm{CO}}$ to predict $\mathrm{PH}$, efforts have focused on the use of exercise parameters, biomarkers and radiological studies to predict IPF-related PH. Patients with early $\mathrm{PH}$ may have normal resting PA pressures but develop elevated pressures with exertion. Several exercise parameters may be useful in suggesting PH in patients with IPF. Multiple investigators have demonstrated that desaturation on 6MWT is associated with PH. As previously noted, in the Lettieri study, IPF patients with $\mathrm{PH}$ had a lower oxygen saturation nadir $(80.1 \pm 3.7 \%$ vs. $88.0 \pm 3.5 \%, p<0.001)$ and decreased distance walked $(143.5 \pm 65.5 \mathrm{~m}$ vs. $365.9 \pm 81.8 \mathrm{~m}, p<0.001)$ on 6MWT [13]. In another series, desaturation to $<85 \%$ on 6MWT was $100 \%$ sensitive for PH, but not specific [17]. Other investigators have demonstrated that more severe exercise limitation is associated with higher pulmonary pressures 
by echocardiography $[21,43]$. Therefore, desaturation greater than expected, or severe limitation on exercise testing should prompt consideration of $\mathrm{PH}$. Another exercise parameter that has been used to evaluate for $\mathrm{PH}$ is the heart rate recovery (HRR), defined as the difference between the heart rate at the end of the 6MWT and after one minute of recovery. Recently, Swigris et.al found that a HRR $<13$ beats/minute had negative and positive predictive values of $82 \%$ and $41 \%$, respectively, for pulmonary hypertension, and also predicted increased mortality [44].

Serum brain natriuretic peptide (BNP) levels are elevated in $\mathrm{PH}$, and are strongly correlated with increased mortality in interstitial lung disease [45]. Leuchte et al. showed that in patients with lung fibrosis, those with elevated levels had significantly higher PAP on RHC than those with normal BNP levels (mPAP $40.9 \mathrm{mmHg}$ vs. $23.4 \mathrm{mmHg}$ ) [46]. The specific role of BNP levels in the diagnosis of $\mathrm{PH}$ remains to be defined.

CT has also been used to evaluate for pulmonary hypertension. In a general population, increased pulmonary artery size as indicated by the ratio of the diameter of the main pulmonary artery to aortic diameter $>1$ has been shown to be an indicator of PH [47]. However, in patients with IPF, no $\mathrm{CT}$ findings, including mean pulmonary artery diameter and ratio of pulmonary artery to aortic diameter, were able to differentiate between those with and without $\mathrm{PH}$ [48]. It has been suggested that a cutoff of $29 \mathrm{~mm}$ for the mean pulmonary artery diameter has reasonable negative predictive value, albeit poor positive predictive value for the presence of $\mathrm{PH}$, implying that IPF patients with measurements below this value may not require further evaluation with RHC [49, 50]. In summary, the cumulative data suggests that the performance characteristics of the PA size as a predictor of PH lacks sufficient accuracy to be solely relied upon.

Estimation of pulmonary artery systolic pressure (PASP) by echocardiographic assessment of the tricuspid regurgitant jet has long been used as a widely available and noninvasive surrogate for RHC measurement of pulmonary pressures. However, the TR jet may be absent or not visualized. Additionally, obtained values may both overestimate and underestimate values for PASP compared to the gold standard right heart catheterization. In patients with advanced lung disease, including those with IPF, the PASP can only be estimated in approximately half of patients, and in those cases where it is estimated, approximately half of patients may be misclassified as having PH [17, 24]. These data indicate that although echocardiography may be a useful part of an overall assessment for $\mathrm{PH}$, it does not replace RHC for the definitive diagnosis. Use of noninvasive tests in combination has appeal in order to improve the overall accuracy of predicting $\mathrm{PH}$. For example, it has recently been shown that a combination of CT findings and echocardiographic findings together was more predictive of $\mathrm{PH}$ by
RHC than either study alone [51]. Future efforts should concentrate on identifying which combinations of tests best identifies or excludes PH and most closely correlates with right heart catheterization data. At this time however, RHC remains the gold standard for the diagnosis of $\mathrm{PH}$ in all patient groups.

\section{Treatment}

Therapy for patients with PH-IPF can be divided into conservative, or non-pharmacologic interventions, and vasoactive medications. Non-pharmacologic interventions include addressing comorbidities such as resting hypoxia, sleepdisordered breathing, as well as cardiovascular and thromboembolic disease. Long-term oxygen therapy (LTOT) is widely accepted as empiric therapy for patients with IPF when the $\mathrm{PaO} 2<60 \mathrm{mmHg}$, with a goal to maintain the $\mathrm{SpO} 2>90 \%$. There is no evidence that LTOT improves survival or pulmonary hemodynamics in IPF [52]. Similarly, supplemental oxygen has not been shown to prevent increases in mPAP during exercise in this population [7]. However, limited data support a potential benefit in improving exercise capacity [53, 54], and current guidelines recommend the use of LTOT in PH-IPF in the setting of resting hypoxemia [55].

An assessment for and the treatment of sleep-disordered breathing is prudent, given the ability to effectively diagnose obstructive sleep apnea (OSA) with nocturnal polysomnography, and the potential for CPAP therapy to improve nocturnal desaturations and quality of life. OSA has a high prevalence in patients with IPF ( $88 \%$ ) [56], and both sleep apnea and chronic nocturnal hypoxia can potentially lead to or perpetuate $\mathrm{PH}$.

At the present time, there is limited data regarding the safety and efficacy of vasoactive therapies for PH-IPF. Vasodilators have demonstrated benefits for certain clinical endpoints such as exercise and functional capacity, but not survival (Table 2) [42, 57-66, 67•, 68, 69]. Vasodilators have the potential to worsen hypoxemia in IPF by inhibiting hypoxic vasoconstriction in regions with low ventilation to perfusion ratios $[57,60,70]$. Additionally, the existence of pulmonary veno-occlusive disease (PVOD)-type lesions have been described in up to two-thirds of patients with IPF, and may be associated with acute pulmonary edema with the use of vasodilator therapy [38, 71-73]. Current guidelines recommend against the routine use of vasodilator agents in patients with PH-IPF, with the caveat that these agents may be considered in specific subgroups of patients, such as those with severe PH (mPAP> $>35 \mathrm{mmHg}$ ) [55]. This is best done in the setting of a clinical trial or an experienced center.

Three small studies ( $n \leq 10$ patients each) have demonstrated that inhaled nitric oxide (iNO) is selective for pulmonary vasodilation, preserves gas exchange and reduces 
Table 2 Trials of therapy for pulmonary hypertension in advanced ILD and IPF

\begin{tabular}{|c|c|c|c|c|}
\hline Author & Type of Study & $N$ & Therapy & Outcome \\
\hline Yoshida et al. 1997 [66] & Case series & 10 & $\mathrm{iNO}$ and $\mathrm{iO}_{2}$ & $\begin{array}{l}\text { Positive study: Reduced PVR and mPAP, } \\
\text { with } \uparrow \text { in } \mathrm{PaO} 2 \text { in } 5 / 10 \text { patients }\end{array}$ \\
\hline Olschewski et al. 1999 [57] & Prospective cohort & 8 & $\begin{array}{l}\text { IV prostacyclin, } \\
\text { iNO, aerosolized } \\
\text { prostacyclin, } \mathrm{iO}_{2}, \\
\text { CCB }\end{array}$ & $\begin{array}{l}\text { Equivocal study: Aerosolized prostacyclin } \\
\text { (iloprost) caused marked pulmonary vasodilation } \\
\text { with maintenance of gas exchange and systemic } \\
\text { arterial pressure; intravenous prostacyclin } \\
\text { increased shunt flow and was not selective for } \\
\text { pulmonary vasculature }\end{array}$ \\
\hline Ghofrani et al. 2002 [60] & RCT, open-label & 16 & Sildenafil & $\begin{array}{l}\text { Positive study: Improved gas exchange and } \\
\text { selective pulmonary vasodilation }\end{array}$ \\
\hline Madden et al. 2006 [69] & Prospective cohort & $\begin{array}{l}7 \text { (mixed study } \\
\text { population, } 3 \\
\text { patients with IPF) }\end{array}$ & Sildenafil & $\begin{array}{l}\text { Positive study: Reduction in PVR, est PAP, CO/CI, } \\
\text { and increased 6MWT and subjective well being; } \\
\text { drug well tolerated }\end{array}$ \\
\hline Madden et al. 2007 [64] & Prospective cohort & $\begin{array}{l}16 \text { (mixed study } \\
\text { population, } 2 \\
\text { patients with IPF) }\end{array}$ & Sildenafil & $\begin{array}{l}\text { Positive study: Significant reduction in mPAP, } \\
6 \mathrm{MWT} \text {, and well tolerated }\end{array}$ \\
\hline Gunther et al. 2007 [61] & Prospective cohort & 12 & Bosentan & Positive study: No worsening of gas exchange \\
\hline Collard et al. 2007 [59] & $\begin{array}{l}\text { Open label } \\
\text { prospective trial }\end{array}$ & 11 & Sildenafil & $\begin{array}{l}\text { Positive study: } 57 \% \text { had an increase in } 6 \mathrm{MWT} \\
\text { distance of } \approx 50 \text { meters }\end{array}$ \\
\hline King et al. 2008 [63] & RCT, double-blind & 158 & Bosentan & $\begin{array}{l}\text { Negative study: No improvement in primary } \\
\text { outcome measure of } 6 \mathrm{MWT} \text { distance, but trends } \\
\text { toward improvements in QOL and delayed } \\
\text { progression of disease or delay in death }\end{array}$ \\
\hline Minai et al. 2008 [65] & $\begin{array}{l}\text { Retrospective } \\
\text { case series }\end{array}$ & 19 & $\begin{array}{l}\text { IV epoprostenol } \\
\text { and bosentan }\end{array}$ & $\begin{array}{l}\text { Equivocal study: Initial, but non-sustained, } \\
\text { functional benefit and improved 6MWT distance }\end{array}$ \\
\hline Zisman et al. $2010[67 \bullet]$ & RCT, double-blind & 180 & Sildenafil & $\begin{array}{l}\text { Negative study: Primary outcome of increased } \\
\text { 6MWT distance not met; small but significant } \\
\text { improvements in secondary outcome measures }\end{array}$ \\
\hline Jackson et al. 2010 [62] & RCT, double-blind & 29 & Sildenafil & $\begin{array}{l}\text { Negative study: No difference in } 6 \mathrm{MWT} \text { or Borg } \\
\text { score }\end{array}$ \\
\hline King et al. 2011 [42] & RCT, double-blind & 616 & Bosentan & $\begin{array}{l}\text { Negative study: Primary outcome of delay in IPF } \\
\text { progression or delay of death not met; no impact } \\
\text { on other secondary outcomes such as quality of } \\
\text { life or dyspnea; medication well tolerated }\end{array}$ \\
\hline Blanco et al. 2011 [68] & Case series & 7 & iNO & $\begin{array}{l}\text { Positive study: iNO significantly decreased PVR } \\
\text { both at rest and during exercise without worsening } \\
\text { oxygenation }\end{array}$ \\
\hline
\end{tabular}

$I P F$ idiopathic pulmonary fibrosis, $R C T$ randomized clinical trial, $6 M W T$ 6-minute walk test, $N Y H A / W H O$ New York Heart Association and World Health Organization, $I V$ intravenous, $i N O$ inhaled nitric oxide, $i O_{2}$ inhaled oxygen, $C C B$ calcium channel blockers, $P A S P$ pulmonary artery systolic pressure, $T T E$ transthoracic echocardiography, $C I$ cardiac index, $C O$ cardiac output, $R H C$ right heart catheterization, $m P A P$ mean pulmonary artery pressure, $P V R$ pulmonary vascular resistance, $I L D$ interstitial lung disease

pulmonary vascular resistance (PVR) $[57,66,68]$. There is no literature on clinical outcomes, as iNO is currently unavailable on a long-term ambulatory basis.

Several smaller studies on sildenafil have yielded conflicting outcomes [59, 60, 62, 64, 69]. A placebo-controlled trial of sildenafil was performed in 180 patients with IPF to evaluate the impact on exercise performance (6-minute walk) [67•]. Although this study failed to demonstrate an improvement in the primary endpoint, there were significant improvements in secondary endpoints including dyspnea, and quality of life, as well as a trend towards a survival benefit. While this study was limited by a lack of RHC data, it likely included a significant number of patients with PH-IPF given the main inclusion criteria of DLco $<35 \%$. A pre-specified post-hoc analysis of those with TTE-evidence of PH demonstrated a significant improvement in the primary endpoint [74].

The dual endothelin receptor antagonist bosentan appears to be safe in IPF $[42,61,63,65]$; however, efficacy appears to be limited. In a phase 3 study (BUILD-1) [63] evaluating its antifibrotic properties, no significant benefit was demonstrated in improving the primary endpoint of 6-minute walk distance. There were trends towards improvements in secondary endpoints, including delayed disease progression, time to death and quality of life. Subgroups analysis of the 
patients in this study with $\mathrm{PH}$ was not possible due to limitations of the study design. However, a follow-up study (BUILD-3) [42] performed to evaluate the endpoint of delayed disease progression and time to death, failed to find any significant differences. Ambrisentan has been studied in patients with PH-IPF (Artemis-PH study [41]); however, this study was terminated early due to potential harm in IPF patients in the parallel Artemis-IPF study. The inhaled prostacyclin iloprost has been studied in patients with echocardiographic evidence of $\mathrm{PH}$, but also with negative results [58]. Preliminary studies on the oral dual endothelin receptor antagonist macitentan in patients with IPF also found this endothelin antagonist to be of no discernible benefit $[75,76]$.

Further studies of currently available and future $\mathrm{PH}$ drugs are strongly encouraged to better define the phenotype of patients (if any) most likely to respond to this therapeutic strategy. A search of http://clinicaltrials.gov (June 14th, 2012) yielded few active studies looking specifically at PHIPF ("idiopathic pulmonary fibrosis," "pulmonary hypertension," "pulmonary hypertension and IPF," and "pulmonary hypertension and pulmonary fibrosis"). Pending the availability of such studies, if off-label PH therapy is to be considered in IPF, it should be done with patients fully informed of the potential effects, both helpful and harmful, and with their full consent and close serial monitoring. This is best achieved in the context of Tertiary Care referral Centers with experience in both IPF and PH.

Lung transplantation is presently the only therapy that confers a survival advantage [77]. Given the lack of other effective therapies, and the progressive nature of this disease, IPF is a leading indication for transplant $[78,79]$. The 5-year survival varies between 44-56\% [55, 78, 80-83], and transplant should therefore be regarded as more of a palliative procedure, rather than a cure. It is controversial as to whether single lung transplants (SLT) or bilateral lung transplants (BLT)) are the optimal procedure for patients with IPF. Any potential advantage of BLT should be weighed against the risk of longer wait times and the inherent risk of dying on the transplant list [84]. Barriers that limit the timeliness of transplant include delays in the diagnosis and referral to a transplant center, as well as the availability of donor organs [85].

\section{Future directions}

Gene microarray technology has been used to identify unique genetic signatures in lung tissue. Gene expression profiles from patients with idiopathic pulmonary arterial hypertension (IPAH) and secondary PH (such as PH-IPF) have the potential to help better define individual risk factors for pulmonary vascular disease, disease progression, and response to therapy [86].

Rajkumar and colleagues [87] evaluated genes involved in the pathogenesis of $\mathrm{PH}$ and generated a molecular signature of 4,734 genes that discriminated between patients with IPAH, PH-IPF, and normals. Tissue specimens were taken from patients undergoing lung and heart-lung transplantation. Numerous signaling pathways were implicated in the pathophysiology of $\mathrm{PH}$, and the genetic signatures and resultant biologic pathways differed between IPAH and PH-IPF.

A recent study by Mura et al. [88••] further delineated the differences between IPF patients with and without associated $\mathrm{PH}$, using microarray analysis of lung specimens. This study identified a genetic signature of 222 differentially expressed genes distinguishing IPF patients with and without PH. Patients were grouped based on right heart catheterization (Severe PH: $\mathrm{mPAP} \geq 40 \mathrm{mmHg}$, Intermediate $P H: 21-29$ $\mathrm{mmHg}$, No $P H: \leq 20 \mathrm{mmHg}$ ), and were well matched with regards to demographic and clinical characteristics, with the exception of $\mathrm{DL}_{\mathrm{CO}}$. Those with Severe $\mathrm{PH}$ had increased expression of genes related to extracellular matrix remodeling, fibroblast migration, and pulmonary artery smooth muscle cell proliferation and migration. The genetic signature of PH-IPF appears to be pro-proliferative, with $\mathrm{PH}$ driven by aberrant proliferation of fibroblasts and pulmonary artery smooth muscle cells. By contrast, genes upregulated in the No PH group consisted primarily of proinflammatory cytokines and cytokine receptors.

Studies on genetic signatures of PH and IPF improve our understanding of the complex pathophysiology and interplay of both. In the future, genomic fingerprinting may assist in identifying the pathways implicated in the pathophysiology of IPF and PH, and enable a pharmacogenetic approach to therapy. Gene expression profiling of either lung specimens or peripheral blood cells may also find utility as biomarkers of disease, and to screen at-risk populations for IPF or established IPF patients for their propensity to develop complicating PH. Ultimately, correlating the effectiveness of a therapy with unique genetic signatures could improve efforts to prevent disease progression in IPF-PH.

\section{Conclusion}

PH has a high prevalence among patients with IPF and independently worsens outcomes. While noninvasive strategies are valuable for screening and risk stratification, only RHC is appropriate to establish the diagnosis. Supplemental oxygen and treatment of other comorbidities should be part of any comprehensive treatment strategy. Randomized controlled studies of pulmonary vasoactive agents have mostly been negative to date, but there remains suggestive evidence that such a targeted approach might be of use in appropriate patients [67•]. Genetic profiling may be the ultimate tool that best identifies such patients and may hold the key to future individualized targeted therapies in both PH and IPF, as well as PH complicating the course of IPF. 
Acknowledgments The views expressed in this article are those of the authors and do not necessarily reflect the official policy or position of the Department of the Army, Department of Defense, or the US Government.

Disclosure J. Sherner: none; J. Collen: none; C. S. King: none; S. D. Nathan: consultant (Intermune, Gilead, United Therapeutics, and Actelion) and honoraria (Gilead, Actelion, and United Therapeutics).

\section{References}

Papers of particular interest, published recently, have been highlighted as:

- Of importance

-. Of major importance

1. Idiopathic Pulmonary Fibrosis Clinical Research Network, et al. Prednisone, azathioprine, and $\mathrm{N}$-acetylcysteine for pulmonary fibrosis. N Engl J Med. 2012;366(21):1968-77.

2. Caminati A, Harari S. IPF: New insight in diagnosis and prognosis. Respir Med. 2010;104 Suppl 1:S2-10.

3. Nathan SD, Noble PW, Tuder RM. Idiopathic pulmonary fibrosis and pulmonary hypertension: connecting the dots. Am J Respir Crit Care Med. 2007;175(9):875-80.

4. Humbert M, McLaughlin VV. The 4th World Symposium on Pulmonary Hypertension. Introduction. J Am Coll Cardiol. 2009;54(1 Suppl):S1-2.

5. Hamada K, et al. Significance of pulmonary arterial pressure and diffusion capacity of the lung as prognosticator in patients with idiopathic pulmonary fibrosis. Chest. 2007;131(3):650-6.

6. Hawrylkiewicz I, et al. Pulmonary haemodynamics at rest and on exercise in patients with idiopathic pulmonary fibrosis. Bull Eur Physiopathol Respir. 1982;18(3):403-10.

7. Pouwels-Fry S, et al. Effects of oxygen on exercise-induced increase of pulmonary arterial pressure in idiopathic pulmonary fibrosis. Sarcoidosis Vasc Diffuse Lung Dis. 2008;25(2):133-9.

8. Weitzenblum E, et al. Pulmonary hemodynamics in idiopathic pulmonary fibrosis and other interstitial pulmonary diseases. Respiration. 1983;44(2):118-27.

9. King Jr TE, et al. Predicting survival in idiopathic pulmonary fibrosis: scoring system and survival model. Am J Respir Crit Care Med. 2001;164(7):1171-81.

10. Agarwal R, et al. Noninvasive estimation of clinically asymptomatic pulmonary hypertension in idiopathic pulmonary fibrosis. Indian $\mathrm{J}$ Chest Dis Allied Sci. 2005;47(4):267-71.

11. Nadrous HF, et al. Pulmonary hypertension in patients with idiopathic pulmonary fibrosis. Chest. 2005;128(4):2393-9.

12. Lederer DJ, et al. Six-minute-walk distance predicts waiting list survival in idiopathic pulmonary fibrosis. Am J Respir Crit Care Med. 2006;174(6):659-64.

13. Lettieri CJ, et al. Prevalence and outcomes of pulmonary arterial hypertension in advanced idiopathic pulmonary fibrosis. Chest. 2006;129(3):746-52.

14. Nathan SD, et al. Pulmonary hypertension and pulmonary function testing in idiopathic pulmonary fibrosis. Chest. 2007;131 (3):657-63.

15. Daniels CE, Yi ES, Ryu JH. Autopsy findings in 42 consecutive patients with idiopathic pulmonary fibrosis. Eur Respir J. 2008;32 (1):170-4.

16. Shorr AF, et al. Pulmonary hypertension in patients with pulmonary fibrosis awaiting lung transplant. Eur Respir J. 2007;30(4):715-21.
17. Nathan SD, et al. Right ventricular systolic pressure by echocardiography as a predictor of pulmonary hypertension in idiopathic pulmonary fibrosis. Respir Med. 2008;102(9):1305-10.

18. Nathan SD, et al. Serial development of pulmonary hypertension in patients with idiopathic pulmonary fibrosis. Respiration. 2008;76(3):288-94.

19. Todd NW, et al. Variable prevalence of pulmonary hypertension in patients with advanced interstitial pneumonia. J Heart Lung Transplant. 2010;29(2):188-94.

20. Modrykamien AM, et al. Echocardiography, 6-minute walk distance, and distance-saturation product as predictors of pulmonary arterial hypertension in idiopathic pulmonary fibrosis. Respir Care. 2010;55 (5):584-8.

21. Boutou AK, et al. Exercise capacity in idiopathic pulmonary fibrosis: the effect of pulmonary hypertension. Respirology. 2011;16(3):451-8.

22. Papakosta D, et al. Prevalence of pulmonary hypertension in patients with idiopathic pulmonary fibrosis: correlation with physiological parameters. Lung. 2011;189(5):391-9.

23. Andersen CU, et al. Pulmonary hypertension in interstitial lung disease: prevalence, prognosis and 6 min walk test. Respir Med. 2012;106(6):875-82.

24. Arcasoy SM, et al. Echocardiographic assessment of pulmonary hypertension in patients with advanced lung disease. Am J Respir Crit Care Med. 2003;167(5):735-40.

25. Nadrous HF, et al. The impact of pulmonary hypertension on survival in patients with idiopathic pulmonary fibrosis. Chest. 2005;128(6 Suppl):616S-7.

26. Harari S, et al. Prognostic value of pulmonary hypertension in patients with chronic interstitial lung disease referred for lung or heart-lung transplantation. J Heart Lung Transplant. 1997;16 (4):460-3.

27. Fitton TP, et al. Impact of secondary pulmonary hypertension on lung transplant outcome. J Heart Lung Transplant. 2005;24 (9):1254-9.

28. Huerd SS, et al. Secondary pulmonary hypertension does not adversely affect outcome after single lung transplantation. J Thorac Cardiovasc Surg. 2000;119(3):458-65.

29. Whelan TP, et al. Effect of preoperative pulmonary artery pressure on early survival after lung transplantation for idiopathic pulmonary fibrosis. J Heart Lung Transplant. 2005;24(9):1269-74.

30. Fang A, et al. Elevated pulmonary artery pressure is a risk factor for primary graft dysfunction following lung transplantation for idiopathic pulmonary fibrosis. Chest. 2011;139(4):782-7.

31. Kuntz CL, et al. Risk factors for early primary graft dysfunction after lung transplantation: a registry study. Clin Transplant. 2009;23(6):819-30.

32. Song JW, Song JK, Kim DS. Echocardiography and brain natriuretic peptide as prognostic indicators in idiopathic pulmonary fibrosis. Respir Med. 2009;103(2):180-6.

33. Mejia $\mathrm{M}$, et al. Idiopathic pulmonary fibrosis and emphysema: decreased survival associated with severe pulmonary arterial hypertension. Chest. 2009;136(1):10-5.

34. Judge EP, et al. Acute exacerbations and pulmonary hypertension in advanced idiopathic pulmonary fibrosis. Eur Respir J. 2011.

35. Farkas L, Kolb M. Pulmonary microcirculation in interstitial lung disease. Proc Am Thorac Soc. 2011;8(6):516-21.

36. Naeije R, Barbera JA. Pulmonary hypertension associated with COPD. Crit Care. 2001;5(6):286-9.

37. Pitsiou G, Papakosta D, Bouros D. Pulmonary hypertension in idiopathic pulmonary fibrosis: a review. Respiration. 2011;82 (3):294-304.

38. Colombat $\mathrm{M}$, et al. Pulmonary vascular lesions in end-stage idiopathic pulmonary fibrosis: Histopathologic study on lung explant specimens and correlations with pulmonary hemodynamics. Hum Pathol. 2007;38(1):60-5. 
39. Renzoni EA, et al. Interstitial vascularity in fibrosing alveolitis. Am J Respir Crit Care Med. 2003;167(3):438-43.

40. Corte TJ, Wort SJ, Wells AU. Pulmonary hypertension in idiopathic pulmonary fibrosis: a review. Sarcoidosis Vasc Diffuse Lung Dis. 2009;26(1):7-19.

41. ARTEMIS-IPF: A Phase 3, Randomized, Double-Blind, PlaceboControlled, Multi-Center, Parallel-Group, Event Driven Study to Evaluate the Efficacy and Safety of Ambrisentan in Subjects With Early Idiopathic Pulmonary Fibrosis (IPF). http://clinicaltrials.gov/ ct2/show/NCT00768300 (Accessed 14 June 2012).

42. King Jr TE, et al. BUILD-3: a randomized, controlled trial of bosentan in idiopathic pulmonary fibrosis. Am J Respir Crit Care Med. 2011;184(1):92-9.

43. Glaser S, et al. Impact of pulmonary hypertension on gas exchange and exercise capacity in patients with pulmonary fibrosis. Respir Med. 2009;103(2):317-24.

44. Swigris JJ, et al. Heart rate recovery after six-minute walk test predicts pulmonary hypertension in patients with idiopathic pulmonary fibrosis. Respirology. 2011;16(3):439-45.

45. Corte TJ, et al. Elevated brain natriuretic peptide predicts mortality in interstitial lung disease. Eur Respir J. 2010;36(4):819-25.

46. Leuchte $\mathrm{HH}$, et al. Brain natriuretic peptide and exercise capacity in lung fibrosis and pulmonary hypertension. Am J Respir Crit Care Med. 2004;170(4):360-5.

47. Ng CS, Wells AU, Padley SP. A CT sign of chronic pulmonary arterial hypertension: the ratio of main pulmonary artery to aortic diameter. J Thorac Imag. 1999;14(4):270-8.

48. Zisman DA, et al. High-resolution chest $\mathrm{CT}$ findings do not predict the presence of pulmonary hypertension in advanced idiopathic pulmonary fibrosis. Chest. 2007;132(3):773-9.

49. Chen $\mathrm{H}$, et al. Utility of $\mathrm{CT}$ for predicting pulmonary hypertension in patients with parenchymal lung disease: similar results, different conclusion? Chest. 2008;133(4):1053-4. author reply 1054.

50. Tan RT, et al. Utility of CT scan evaluation for predicting pulmonary hypertension in patients with parenchymal lung disease. Medical College of Wisconsin Lung Transplant Group. Chest. 1998;113 (5):1250-6.

51. Devaraj A, et al. Detection of pulmonary hypertension with multidetector CT and echocardiography alone and in combination. Radiology. 2010;254(2):609-16.

52. Bradley B, et al. Interstitial lung disease guideline: the British Thoracic Society in collaboration with the Thoracic Society of Australia and New Zealand and the Irish Thoracic Society. Thorax. 2008;63 Suppl 5:v1-58.

53. Hallstrand TS, et al. The timed walk test as a measure of severity and survival in idiopathic pulmonary fibrosis. Eur Respir J. 2005;25(1):96-103.

54. Morrison DA, Stovall JR. Increased exercise capacity in hypoxemic patients after long-term oxygen therapy. Chest. 1992;102(2):542-50.

55. Raghu G, et al. An official ATS/ERS/JRS/ALAT statement: idiopathic pulmonary fibrosis: evidence-based guidelines for diagnosis and management. Am J Respir Crit Care Med. 2011;183(6):788-824.

56. Lancaster LH, et al. Obstructive sleep apnea is common in idiopathic pulmonary fibrosis. Chest. 2009;136(3):772-8.

57. Olschewski $\mathrm{H}$, et al. Inhaled prostacyclin and iloprost in severe pulmonary hypertension secondary to lung fibrosis. Am J Respir Crit Care Med. 1999;160(2):600-7.

58. Krowka MJ, Ahmad S, Andrade JA, Frost A, Glassberg M, Lancaster $\mathrm{L}$, et al. A randomized, double-blind, placebo-controlled study to evaluate the safety and efficacy of iloprost inhalation in adults with abnormal pulmonary arterial pressure and exercise limitation associated with idiopathic pulmonary fibrosis [meeting abstact]. Chest. 2007;132:633S.

59. Collard HR, et al. Sildenafil improves walk distance in idiopathic pulmonary fibrosis. Chest. 2007;131(3):897-9.
60. Ghofrani HA, et al. Sildenafil for treatment of lung fibrosis and pulmonary hypertension: a randomised controlled trial. Lancet. 2002;360(9337):895-900.

61. Gunther A, et al. Safety and tolerability of bosentan in idiopathic pulmonary fibrosis: an open label study. Eur Respir J. 2007;29 (4):713-9.

62. Jackson RM, et al. Sildenafil therapy and exercise tolerance in idiopathic pulmonary fibrosis. Lung. 2010;188(2):115-23.

63. King Jr TE, et al. BUILD-1: a randomized placebo-controlled trial of bosentan in idiopathic pulmonary fibrosis. Am J Respir Crit Care Med. 2008;177(1):75-81.

64. Madden BP, et al. Does Sildenafil produce a sustained benefit in patients with pulmonary hypertension associated with parenchymal lung and cardiac disease? Vasc Pharmacol. 2007;47(2-3):184-8.

65. Minai OA, et al. Vaso-active therapy can improve 6-min walk distance in patients with pulmonary hypertension and fibrotic interstitial lung disease. Respir Med. 2008;102(7):1015-20.

66. Yoshida M, et al. The effect of low-dose inhalation of nitric oxide in patients with pulmonary fibrosis. Eur Respir J. 1997;10(9):2051-4.

67. - Zisman DA, et al. A controlled trial of sildenafil in advanced idiopathic pulmonary fibrosis. N Engl J Med. 2010;363(7):620-8. The largest and highest quality clinical trial evaluating the efficacy of vasodilator therapy in IPF patients failed to demonstrate a significant benefit in the primary endpoint of improved $6 M W D$. There were small but statistically significant differences in secondary endpoints. This study demonstrates the failure of vasodilator therapy to have a definitive impact on this population, and highlights the need for further studies specifically evaluating subgroups of IPF patients with $P H$.

68. Blanco I, et al. Effects of inhaled nitric oxide at rest and during exercise in idiopathic pulmonary fibrosis. J Appl Physiol. 2011;110(3):638-45.

69. Madden BP, et al. A potential role for sildenafil in the management of pulmonary hypertension in patients with parenchymal lung disease. Vasc Pharmacol. 2006;44(5):372-6.

70. Strange C, et al. Hemodynamic effects of epoprostenol in patients with systemic sclerosis and pulmonary hypertension. Chest. 2000;118(4):1077-82.

71. Corte TJ, et al. Pulmonary hypertension in sarcoidosis: a review. Respirology. 2011;16(1):69-77.

72. Fartoukh M, et al. Severe pulmonary hypertension in histiocytosis X. Am J Respir Crit Care Med. 2000;161(1):216-23.

73. Montani D, et al. Pulmonary veno-occlusive disease. Eur Respir J. 2009;33(1):189-200.

74. Han MK, Bach D, Hagan P, Schmidt SL, Flaherty KR, Toews GB, et al. Presence of right ventricular dysfunction modifies treatment response to sildenafil in the Step-IPF Trial [abstract]. Am J Respir Crit Care Med. 2011;183:A5301.

75. Raja SG. Macitentan, a tissue-targeting endothelin receptor antagonist for the potential oral treatment of pulmonary arterial hypertension and idiopathic pulmonary fibrosis. Curr Opin Investig Drugs. 2010;11 (9):1066-73.

76. Sidharta PN, et al. Macitentan: entry-into-humans study with a new endothelin receptor antagonist. Eur J Clin Pharmacol. 2011;67(10):977-84.

77. Chan AL, et al. Therapeutic Update in Idiopathic Pulmonary Fibrosis. Clin Rev Allergy Immunol. 2011.

78. Cerri S, et al. Management of idiopathic pulmonary fibrosis. Clin Chest Med. 2012;33(1):85-94.

79. Yusen RD, et al. Lung transplantation in the United States, 1999-2008. Am J Transplant. 2010;10(4 Pt 2):1047-68.

80. Allen S, et al. Low dose diamorphine reduces breathlessness without causing a fall in oxygen saturation in elderly patients with end-stage idiopathic pulmonary fibrosis. Palliat Med. 2005;19(2):128-30.

81. Keating D, et al. Lung transplantation in pulmonary fibrosis: challenging early outcomes counterbalanced by surprisingly good outcomes beyond 15 years. Transplant Proc. 2009;41(1):289-91. 
82. Mason DP, et al. Lung transplantation for idiopathic pulmonary fibrosis. Ann Thorac Surg. 2007;84(4):1121-8.

83. Thabut G, et al. Survival after bilateral versus single-lung transplantation for idiopathic pulmonary fibrosis. Ann Intern Med. 2009;151(11):767-74.

84. Nathan SD, et al. Comparison of wait times and mortality for idiopathic pulmonary fibrosis patients listed for single or bilateral lung transplantation. J Heart Lung Transplant. 2010;29(10):1165-71.

85. Paik HC, et al. The fate of patients on the waiting list for lung transplantation in Korea. Transplant Proc. 2012;44(4):865-9.

86. Geraci MW, Bull TM, Tuder RM. Genomics of pulmonary arterial hypertension: implications for therapy. Heart Fail Clin. 2010;6 (1):101-14.
87. Rajkumar R, et al. Genomewide RNA expression profiling in lung identifies distinct signatures in idiopathic pulmonary arterial hypertension and secondary pulmonary hypertension. Am J Physiol Heart Circ Physiol. 2010;298(4):H1235-48.

88. •• Mura M, et al. Gene expression profiling in the lungs of patients with pulmonary hypertension associated with pulmonary fibrosis. Chest. 2012;141(3):661-73. This article presents a new and promising method for evaluating disease progression and therapy in patients with IPF. IPF patients with and without PH were stratefied by disease severity based on RHC measurements. The genetic signature of IPF-PH was pro-proliferative, while that of the No PH patients was proinflammatory. Genetic differences among IPF patients may explain the failure of current treatment strategies to offer significant benefit in clinical trials. 